\title{
Exploring Antibiotic Resistance Pattern of Escherichia coli, Salmonella spp., and Staphylococcus spp. Isolated from Eggs in Rajshahi
}

Md. Hakimul Haque, Md. Mizanur Rahman, Md. Lovelu Miah, Soshe Ahmed, Md. Rabiul Islam Sazib, Rashida Khaton, Aurangazeb Kabir, and Md. Nasir Uddin

\section{ABSTRACT}

Chicken eggs are a major component of people's diets, with an average yearly consumption of approximately 103 eggs per person in Bangladesh. Eggs act as an important carrier of food-borne pathogen worldwide. The study was conducted to identify the prevalence and antibiotic resistance pattern of E. coli, Salmonella spp., and Staphylococcus spp., in eggs isolated from farms and different markets of Rajshahi, Bangladesh. A total of 60 eggs were collected randomly between April to December 2019. The isolation and identification of bacterial pathogen was done in accordance with standard procedures. The bacterial isolates were subjected to antibiotic susceptibility testing against seven commonly used antibiotics using Kirby-Bauer disk diffusion method. An overall prevalence of $E$. coli, Salmonella spp., and Staphylococcus spp. were found to be $35.0 \%, 28.33 \%$, and $23.33 \%$, respectively. $E$. coli were found highly resistant to penicillin $(\mathbf{1 0 0 \%})$, tetracycline $(\mathbf{8 0 . 9 5 \%})$, ampicillin $(\mathbf{1 0 0 \%})$, and erythromycin $(85.71 \%)$ and were sensitive to amoxicillin $(\mathbf{7 1 . 4 2 \%})$, ciprofloxacin $(85.71 \%)$, and gentamicin $(95.23 \%)$. Salmonella spp. was highly resistant to penicillin $(100 \%)$, erythromycin $(82.35 \%)$ and tetracycline $(82.35 \%)$, and was sensitive to gentamicin $(\mathbf{9 4 . 1 1 \%})$, amoxicillin $(\mathbf{7 6 . 4 7 \%})$ and ciprofloxacin $(\mathbf{7 0 . 5 8 \%})$. Staphylococcus spp. was resistant to penicillin $(\mathbf{1 0 0 \%})$, erythromycin $(\mathbf{7 8 . 5 7 \%})$, tetracycline $(\mathbf{8 5 . 7 1 \%})$, amoxicillin $(\mathbf{1 0 0 \%})$, and ampicillin $(\mathbf{1 0 0 \%})$ but sensitive to ciprofloxacin $(\mathbf{8 5 . 7 1 \%})$, and gentamicin $(\mathbf{9 2 . 8 5 \%})$. The higher prevalence of multidrug-resistant (MDR) bacteria can easily enter the food chain, which poses a public health threat.

Keywords: Antibiotic resistance, Escherichia coli, Salmonella spp., Staphylococcus spp., Eggs.
Submitted : June 21, 2021

Published : July 12, 2021

ISSN: $2684-1827$

DOI: $10.24018 /$ ejfood. 2021.3 .4 .328

Md. Hakimul Haque*

Faculty of Veterinary and Animal Sciences, University of Rajshahi,

Rajshahi-6205, Bangladesh.

(e-mail: hakim.ahvs@ru.ac.bd)

Md. Mizanur Rahman

Faculty of Veterinary and Animal Sciences, University of Rajshahi,

Rajshahi-6205, Bangladesh.

(e-mail:

vetmizanurrahman92@gmail.com)

Md. Lovelu Miah

Faculty of Veterinary and Animal

Sciences, University of Rajshahi, Rajshahi-6205, Bangladesh.

(e-mail: lovelumiah1993@gmail.com)

Soshe Ahmed

Faculty of Veterinary and Animal

Sciences, University of Rajshahi,

Rajshahi-6205, Bangladesh.

(e-mail: soshe.ahmed@gmail.com)

Md. Rabiul Islam Sazib

Faculty of Veterinary and Animal

Sciences, University of Rajshahi,

Rajshahi-6205, Bangladesh.

(e-mail: robiulsazib475@gmail.com)

Rashida Khaton

Faculty of Veterinary and Animal

Sciences, University of Rajshahi,

Rajshahi-6205, Bangladesh.

(e-mail: rashidavet@yahoo.com)

Aurangazeb Kabir

Faculty of Veterinary and Animal

Sciences, University of Rajshahi,

Rajshahi-6205, Bangladesh.

(e-mail: aurangak@yahoo.com)

Md. Nasir Uddin

Faculty of Veterinary and Animal

Sciences, University of Rajshahi,

Rajshahi-6205, Bangladesh.

(e-mail: nasirnahid4@gmail.com)

*Corresponding Author

\section{INTRODUCTION}

The global poultry business has grown tremendously to meet the growing demand for animal proteins for human consumption. According to the Food and Agriculture Organization of the United Nations, annual egg production will reach 100 million tonnes by 2050 due to world population growth [1]. One of the most expensive and ideal consumables is the egg. Eggs contain all of the nutrients required for organisms to develop and survive, including humans. It includes many vitamins A, D, E, K, B12, riboflavin, folic acid, pantothenic acid, zinc, phosphorus, choline, and selenium. At the same time, many of the nutrients included in eggs provide an ideal environment for 
the growth of bacterial microflora, including pathogenic bacteria. Eggs can be contaminated or infected in two ways: horizontally (through the shell) or vertically (transovarially), making them a possible source of pathogens involved in the genesis of food-borne illness in humans [2]. Freshly deposited eggs are generally sterile; however, they can become a public health threat if infected, resulting in economic losses due to spoiling. With the rising popularity of eggs and egg products, it is more important than ever to look into the various variables that can lead to egg contamination. Deposition of faeces on the shell, ovarian or oviduct and gut flora, waste material, egg crates, packing and storage, poultry workers' clothes and hands, dust, the environment, weather conditions, transportation, and marketing can all cause eggshell contamination [3]. As a result, additional study on table eggs is urgently needed to protect poultry, the people, and animal health.

In the last few decades, antibiotics have considerably increased cattle and poultry output worldwide for the prevention and control of a number of bacterial diseases. Antibiotic resistance (ABR) in bacteria has been produced by the overuse and misuse of antibiotics, putting natural microbial systems under a lot of stress [4], [5]. Due to the widespread use of antibiotics as treatments and growth promoters in chicken farms, ABR has emerged as a major concern in clinical practice, representing a significant and global public health threat [6]. Each year, AMR is predicted to kill approximately 700,000 people around the world [7]. Antibiotic-resistant bacteria are now widespread in the environment, posing inversely cabbalistic and contradictory effects on all aspects of one health, including animal, human, and environmental health [8], [9]. The uncontrolled and accidental use of antibiotics in poultry and a lack of fundamental information among the general population contribute to the development of antibiotic-resistant microorganisms in the environment [10]. Poultry, on the other hand, is permitted as a key growing source of ABR because to the tremendous selection pressure for ABR in $E$. coli, Salmonella spp., and Staphylococcus spp. [11]. Furthermore, because antibiotic-resistant bacteria are found in chickens' guts, they can serve as reservoirs for disease transmission from poultry to humans, the environment, and other animals [12]. Antibiotic-resistant Escherichia coli, Salmonella spp., and Staphylococcus spp. can also infect poultry farm environmental settings like feed, litter, water, air, and human hand washing through chicken droppings and table eggs. These resistant bacteria built up in the farm environment can be transmitted directly to farm workers, posing a significant human health risk [13].

E. coli, a zoonotic commensal pathogen, is a major organism in the global chicken industry, causing massive economic losses [14], [15]. Although most E. coli strains are non-pathogenic, only a few strains cause gastrointestinal (GI) illness since they are ubiquitous in the GI tract as part of both humans' and animals' natural microbial flora [16]. Furthermore, pathogenic E. coli strains can cause UTIs, abdominal sepsis, meningitis, and septicemia in humans, resulting in zoonotic disease [17]. Salmonella spp. is common food-borne pathogens that can also be zoonotic [18]. Poultry can serve as natural reservoirs for Salmonella spp., which can then be transmitted to humans and cause
Salmonellosis, including septicemia, enteric fever, and gastroenteritis [19], [20]. Several Salmonella serotypes have developed resistance to commonly used antibiotics, raising manufacturing costs [21]. Staphylococcus spp. is one of the most common human opportunistic pathogens, producing everything from minor skin infections to infective endocarditis, osteomyelitis, bacteremia, and necrotizing pneumonia [22]. Some strains of Staphylococcus spp. have developed a high level of resistance, such as methicillinresistant Staphylococcus aureus (MRSA), which is resistant to nearly every antibiotic used to treat Staphylococcal infections [23], [24]. In today's medicine, the development of antibiotic resistance in commensal bacteria is a critical and developing concern. Surveillance data on the presence of AMR bacteria in Bangladesh's chicken farming system, particularly table eggs, is crucial for developing AMRrelated risk mitigation strategies. In light of the foregoing, the current investigation was conducted to isolate, identify, and profile the antibiotic sensitivity pattern of E. coli, Salmonella spp., and Staphylococcus spp. in table eggs from several retail markets in Rajshahi.

\section{MATERIALS AND METHODS}

\section{A. Sources and Collection of Samples}

In sterile polythene bags, 60 egg samples were collected from several retail markets in Rajshahi city. The samples were then immediately sent to the Department of Veterinary and Animal Sciences, Rajshahi University, for bacteriological investigation, all while maintaining sterile and cold chain conditions. Eggshell surface samples were collected in the laboratory using moist cotton swabs and gentle rubbing. The Institutional Animal, Medical Ethics, Biosafety, and Biosecurity Committee (IAMEBBC) of the University of Rajshahi's Institute of Biological Science (IBSc) granted ethical approval for experiments on animals, humans, microbes, and living natural sources (Memo no:144/320/I.A.M.E.B.B.C./IBSc). All of the procedures were carried out under the applicable rules and regulations.

\section{B. Isolation and Preservation of Bacteria}

The samples were initially inoculated onto nutrient broth and immediately incubated at $37{ }^{\circ} \mathrm{C}$ for 24 hours following collection. Next, the bacteria were injected onto nutrient agar (NA) plates using the streak plate method after primary growth in nutrient broth and incubated at $37{ }^{\circ} \mathrm{C}$ for 24 hours. Finally, single individual colonies of different characteristics were injected into NA plates from the primary culture to obtain pure culture (subculture). The cultural procedure will be continued until pure culture is obtained [25]. Both agar slant and 20 percent pure buffered glycerin were used to maintain stock cultures [26].

\section{Identification of Bacteria}

Standard laboratory methods were used to identify the isolated organisms, including staining, motility, colony morphology, string test, and several biochemical assays such as sugar fermentation test, Catalase test, Coagulase test, Methyl red test, Voges-Proskauer test, and Indole test [24]. 


\section{Antibiotic Susceptibility Test}

Antibiotic sensitivity tests were performed using the disc diffusion test, which was modified somewhat from the Kirby-Bauer approach [27]. In a nutshell, 0.5 McFarland standards concentrations of freshly grown broth culture were put onto Mueller-Hinton agar (Hi-Media, India) plates and evenly distributed. Antibiotic discs were aseptically placed on the surface of the inoculation plates using sterile forceps and incubated for 24 hours at $37{ }^{\circ} \mathrm{C}$. The plates were examined after incubation, and the sizes of the inhibitory zones were measured. The sizes were then classified as sensitive (S), intermediate (I), or resistant (R) using the NCCLS (1999) standard diameters (R). Penicillin (10 $\mu \mathrm{g})$, erythromycin $(15 \mu \mathrm{g})$, amoxycillin $(10 \mu \mathrm{g})$, gentamycin $(10 \mu \mathrm{g})$, ciprofloxacin $(5 \mu \mathrm{g})$, and ampicillin $(10 \mu \mathrm{g})$ were utilized for the disc diffusion test. These antibiotics were chosen at random based on their commercial availability and widespread use in the chicken industry in Bangladesh and worldwide.

\section{RESULTS AND DISCUSSION}

\section{A. Overall Prevalence of Bacteria Isolated from Eggs}

The table eggs play crucial role in the everyday diets of millions of people worldwide as it entails high nutritional value and digestibility as well as safety of use. Also, the presence of pathogenic bacteria in table chicken eggs may pose a serious health problem to human health like food poisoning and food-borne infections [28]. This study revealed that $86.67 \%$ of samples (52 out of 60 ) from four randomly selected retail marketplaces in Rajshahi, Bangladesh, tested positive for microbial contamination. Among them, 22 samples $(36.67 \%)$ tested positive for $E$. coli, 18 samples (30\%) tested positive for Salmonella spp., and 12 samples (20\%) tested positive for Staphylococcus spp. (Table I). Escherichia coli are known to contaminate the surface of eggs, while the mechanical process can spread further the bacteria. The present study has demonstrated an overall prevalence $(36.67 \%)$ of $E$. coli contamination in table eggs, where the highest prevalence was recorded $46.67 \%$ at Kazla market and the lowest $20.0 \%$ at Binodpur Bazar. The highest prevalence in the Kazla market was probably due to the poor hygienic practice in the market. This finding agrees with the previous study where the prevalence of $E$. coli was reported as $37.0 \%$ in table eggs [29]. In the present study, Salmonella spp. in table egg from the selective market was $30 \%$. The highest prevalence was $33.33 \%$ at Binodpur and Kazla Bazar, and the lowest was $13.33 \%$ at Station Bazar, RU. Almost similar prevalence of Salmonella spp. (23.52\%) was also reported previously [30]. Contamination of egg by Salmonella spp. may occur at any production stage like collection, transportation, or marketing either through vertical or horizontal transmission. Importantly, reusable egg tray is a potential source for contaminating eggshell by Salmonella spp. in developing country like Bangladesh. Staphylococcus spp. isolation rate in table egg from the different markets was $20 \%$, where the highest prevalence was $26.67 \%$ at Binodpur and Station Bazar, RU and lowest $13.33 \%$ at Kazla and Katakhali Bazar. The above result is lower than the results reported by
Parveen et al., [30]; the referred prevalence of Staphylococcus spp. was $25.49 \%$ in table egg. This is in agreement with Chaemsanit et al. [31], who found isolates from 15 different genera in chicken eggs and their contents, including Staphylococcus spp., Micrococcus spp., Enterococcus spp., Streptococcus spp., Bacillus spp., Corynebacterium spp., Acinetobacter spp., Neisseria spp. [31]. Similarly, Salihu et al. [32] found that 100 percent of egg samples were positive for bacterial (nine different genera) contamination, including Escherichia coli, Salmonella spp., Shigella spp., Corynebacterium spp., Proteus spp., Bacillus spp., Staphylococcus spp., Streptococcus spp. [32]. Hang' Ombe et al. [33] revealed microbial contamination of chicken eggs with primary members of the Enterobacteriaceae family, supporting the current findings [33]. Microorganisms can be discovered on both the exterior and interior of the eggshell, according to this study and USDA [34]. Microorganisms inside an uncracked egg or unbroken egg may be due to the pathogen's presence within the hen's ovary or through the oviduct before the shell forms around the yolk and albumin the egg comes from the hen's body through the same channel as feces is ejected. After the shells have been laid, fecal pollutants could enter through the pores. Egg contamination has been linked to several reasons. Bird faeces, litter, incorrect egg handling by retailers, unsanitary circumstances in markets where these eggs are sold, contaminated egg crates, packing, and poor storage methods are only a few of them [35]. Others include poultry employees' clothes and hands, surroundings, dust conveying marketing, improper retail store storage, and weather conditions.

TABLE I: PREVALENCE OF E. COLI, SALMONELLA SPP. AND STAPHYLOCOCCUS SPP. IN EGG SAMPLES

\begin{tabular}{ccccc}
\hline Source & $\begin{array}{c}\text { E. coli } \\
\text { positive } \\
(\%)\end{array}$ & $\begin{array}{c}\text { Salmonella } \\
\text { spp. positive } \\
(\%)\end{array}$ & $\begin{array}{c}\text { Staphylococcus } \\
\text { spp. positive } \\
(\%)\end{array}$ & $\begin{array}{c}\text { Prevalence } \\
(\%)\end{array}$ \\
\hline Binodpur Bazar & 20 & 33.33 & 26.67 & 80 \\
Kazla Bazar & 46.67 & 33.33 & 13.33 & 93.33 \\
Katakhali & 40 & 40 & 13.33 & 93.33 \\
$\quad$ Bazar & & 13.33 & 26.67 & 80 \\
Station Bazar, & 40 & 30 & 20 & 86.67 \\
RU & 36.67 & & & \\
Total & & &
\end{tabular}

\section{B. Antibiogram Study}

The in-vitro antibiotic sensitivity test results indicated that the isolated $E$. coli showed the highest resistance to penicillin and ampicillin, followed by erythromycin and tetracycline, with $100 \%, 100 \%, 85.71 \%, 88.89 \%$, and $80.95 \%$, respectively. This bacterium, on the other hand, showed the maximum sensitivity to gentamicin (95.23\%), followed by ciprofloxacin $(85.71 \%)$, and amoxicillin (71.42\%) (Table II and Fig. 1).

In our study, Salmonella spp. had the highest resistance patterns against penicillin (100\%), erythromycin (82.35\%), and tetracycline $(82.35 \%)$, while gentamycin, amoxicillin, and ciprofloxacin had the highest sensitivity rates of $94.11 \%, 76.47 \%$, and $70.58 \%$, respectively (Table III and Fig. 2). 
TABLE II: ANTIBACTERIAL SENSitivity AND RESISTANT Pattern of $E$.

\begin{tabular}{|c|c|c|c|c|}
\hline \multirow{2}{*}{$\begin{array}{c}\text { No of } \\
\text { isolates } \\
\text { tested }\end{array}$} & \multirow[b]{2}{*}{$\begin{array}{c}\text { Name of } \\
\text { Antibiotics }\end{array}$} & \multicolumn{3}{|c|}{ Sensitivity pattern } \\
\hline & & $\begin{array}{c}\text { Sensitive } \\
(\%)\end{array}$ & $\begin{array}{l}\text { Intermediate } \\
\text { sensitive }(\%)\end{array}$ & $\begin{array}{c}\text { Resistant } \\
(\%)\end{array}$ \\
\hline \multirow{7}{*}{21} & Penicillin & 0 & 0 & 100 \\
\hline & Erythromycin & $2(9.52)$ & $1(4.77)$ & $18(85.71)$ \\
\hline & Amoxicillin & $15(71.42)$ & $5(23.81)$ & $1(4.77)$ \\
\hline & Tetracycline & $3(14.28)$ & $1(4.77)$ & $17(80.95)$ \\
\hline & Gentamicin & $20(95.23)$ & $1(4.77)$ & 0 \\
\hline & Ciprofloxacin & $18(85.71)$ & $3(14.29)$ & 0 \\
\hline & Ampicillin & 0 & 0 & 100 \\
\hline
\end{tabular}

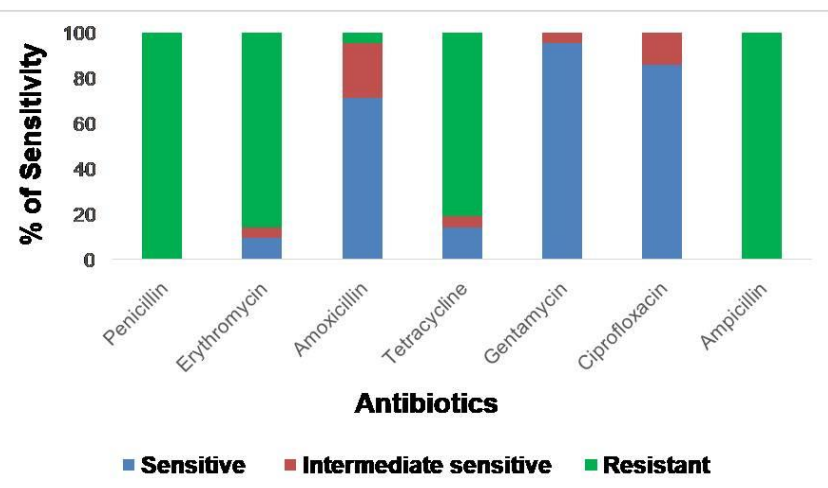

Fig. 1. Antibiotic sensitivity pattern of E. coli isolated from egg samples.

In the case of Staphylococcus spp., the majority of isolates were resistant to penicillin $(100 \%)$, erythromycin (78.57\%), tetracycline $(85.71 \%)$, amoxicillin $(100 \%)$, and ampicillin (100\%), but susceptible to ciprofloxacin (85.71\%), gentamicin (85.71\%), and ampicillin (100\%) (Table IV and Fig. 3). The findings of Papadopoulou [36], who found resistant strains of Staphylococcus aureus (to penicillin-G, tetracycline, erythromycin, clindamycin, cephalosporins, oxacillin, gentamycin, chloramphenicol, and tobramycin), Enterococcus faecalis (to ampicillin, ciprofloxacin, clindamycin.

TABLE III: ANTIBACTERIAL SENSITIVITY AND RESISTANT PATTERN OF SALMONELLA SPP.

\begin{tabular}{|c|c|c|c|c|}
\hline \multirow{2}{*}{$\begin{array}{c}\text { No of } \\
\text { isolates } \\
\text { tested }\end{array}$} & \multirow{2}{*}{$\begin{array}{c}\text { Name of } \\
\text { Antibiotics }\end{array}$} & \multicolumn{3}{|c|}{ Sensitivity pattern } \\
\hline & & $\begin{array}{c}\text { Sensitive } \\
(\%)\end{array}$ & $\begin{array}{l}\text { Intermediate } \\
\text { sensitive (\%) }\end{array}$ & $\begin{array}{c}\text { Resistant } \\
(\%)\end{array}$ \\
\hline \multirow{7}{*}{17} & Penicillin & 0 & 0 & 100 \\
\hline & Erythromycin & $2(11.77)$ & $1(5.88)$ & $14(82.35)$ \\
\hline & Amoxicillin & $13(76.47)$ & $3(17.65)$ & $1(5.88)$ \\
\hline & Tetracycline & $1(5.88)$ & $2(11.77)$ & $14(82.35)$ \\
\hline & Gentamicin & $16(94.11)$ & $1(5.89)$ & 0 \\
\hline & Ciprofloxacin & $12(70.58)$ & $4(23.59)$ & $1(5.88)$ \\
\hline & Ampicillin & 0 & 0 & 100 \\
\hline
\end{tabular}

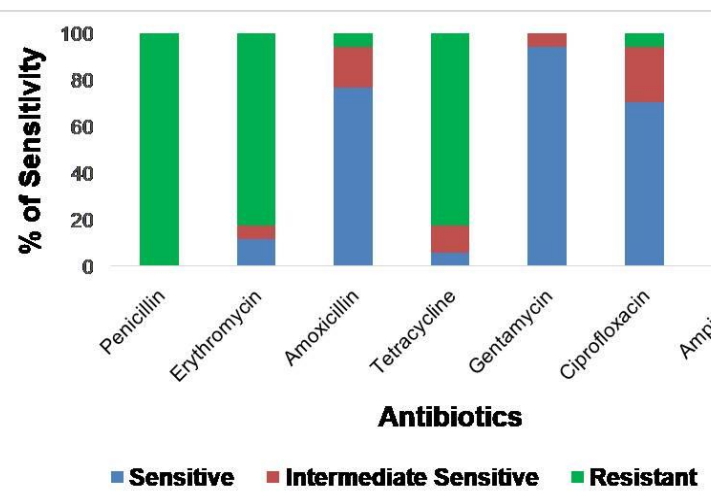

Fig. 2. Antibiotic sensitivity pattern of Salmonella spp. isolated from egg samples.
According to Jain and Yadav [37], isolated bacteria from eggs had the highest resistance rate $(86.66 \%)$ to Cefixime, but the highest sensitivity rate $(100 \%)$ to Gentamicin, Levofloxacin, and Ciprofloxacin. In addition, the majority of the isolates $(73.3 \%)$ were discovered to be multi-drug resistant, meaning they were resistant to three or more antibiotics. According to Eid (2015), 94\% of E. coli isolates were resistant to five or more antibiotics [38]. Another study by Adesiyun $e t$ al. [39] found that $46.6 \%$ of $E$. coli isolates were resistant to three or more antimicrobial drugs. Salmonella isolates were resistant to ampicillin, streptomycin, and tetracycline, according to KilonzoNthenge et al. [40], whereas E. coli isolates were resistant to ampicillin and nalidixic acid. Ampicillin, tetracycline, and gentamycin resistance have also been documented in Salmonella spp. recovered from chickens [41]. E. coli isolated from meat and poultry has been found to be resistant to at least one antimicrobial treatment, according to recent research [42]. S. aureus strains were shown to be resistant to at least one of the antibiotics evaluated by Pyzik and Marek [28], with some (55.55\%) showing resistance to five or more of the 17 therapeutic drugs. Resistance to erythromycin $(66.66 \%)$, tetracycline $(66.66 \%)$, and oxytetracycline $(61.11 \%)$, penicillin $\mathrm{G}(50 \%)$, and amoxicillin was found in the most significant number of strains (44.44\%). The uncontrolled, random, and repeated use of these most resistant bacteria in chicken farms worldwide, including Bangladesh, may have resulted in their growth.

TABLE IV: ANTIBACTERIAL SENSITIVITY AND RESISTANT PATTERN OF STAPHYLOCOCCUS SPP.

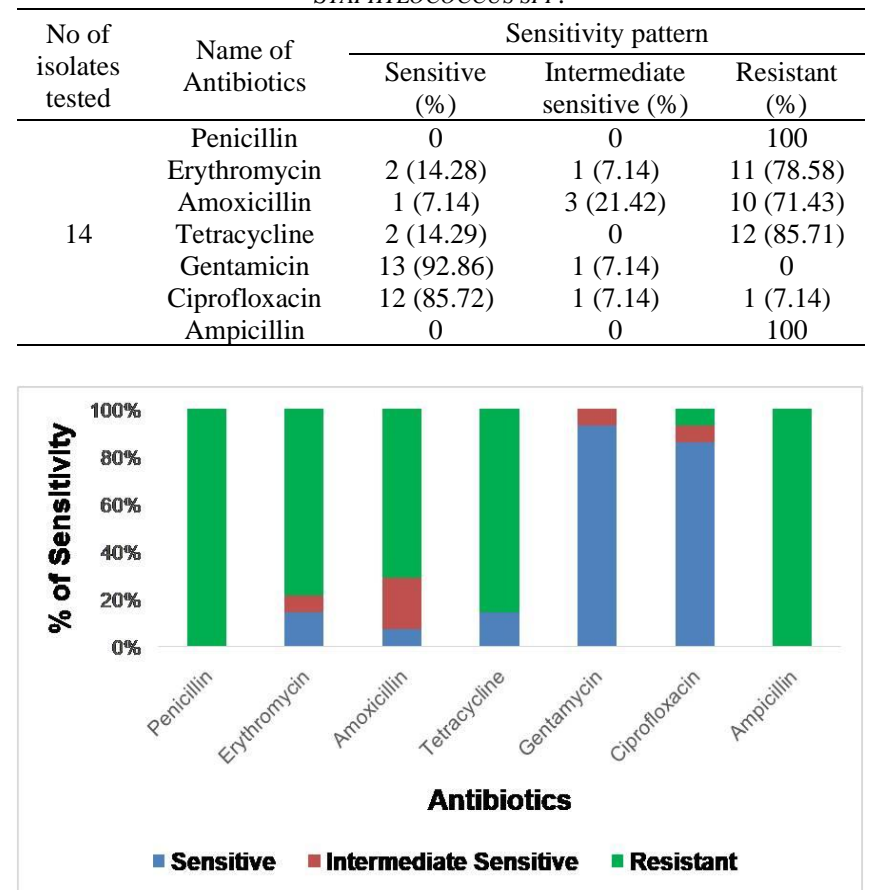

Fig. 3. Antibiotic sensitivity pattern of Staphylococcus spp. isolated from egg samples.

\section{CONCLUSION}

The table eggs of commercial layers are infected with antibiotic-resistant E. coli, Salmonella spp., and Staphylococcus spp. These antibiotic-resistant bacteria could potentially be transmitted to humans through tainted eggs. 
Antibiotic resistance in microorganisms from chicken eggs should be taken seriously as a public health issue.

\section{ACKNOWLEDGMENT}

The authors would like to express their deepest sense of gratitude and sincere thanks to the government of the People's Republic of Bangladesh, Ministry of Science and Technology (MOST), for their financial support for this research work.

\section{CONFLICT OF INTEREST}

The authors declare no conflict of interest.

\section{REFERENCES}

[1] FAO, "the state of food security and nutrition in the world 2018: building climate resilience for food security and nutrition", 2018.

[2] D. Stępień-Pyśniak, "Occurrence of Gram-negative bacteria in hen's eggs depending on their source and storage conditions," Pol. J. Vet. Sci., Vol. 13, pp. 507-513, Jan. 2010.

[3] M. J. Hossain, M. S. Islam, M. A. Sobur, S. B. Zaman, A. Nahar, M. Rahman, M. T. Rahman, "Exploring Poultry Farm Environment for Antibiotic Resistant Escherichia coli, Salmonella spp., and Staphylococcus spp. Having Public Health Significance," J Bangladesh Agril Univ, Vol. 18, pp. 615-622, Sep 2020.

[4] M. H. Haque, S. Sarker, M. S. Islam, et al., "Sustainable AntibioticFree Broiler Meat Production: Current Trends, Challenges, and Possibilities in a Developing Country Perspective," Biology (Basel), Vol. 9, pp. 411, Nov 2020

[5] S. Schwarz, A. Loeffler, K. Kadlec, "Bacterial resistance to antimicrobial agents and its impact on veterinary and human medicine," Vet Dermatol., Vol. 28, pp. 82-e19, Feb 2017.

[6] G. M. Boovaragamoorthy, M. Anbazhagan, P. Piruthiviraj, A. Pugazhendhi, S. S. Kumar, et al., "Clinically important microbial diversity and its antibiotic resistance pattern towards various drugs," $J$ Infect Public Health, Vol. 12, pp. 783-788, Dec 2019.

[7] K Clifford, D. Darash, C. P. da Costa, H. Meyer, M. T. Islam, et al., "The threat of antimicrobial resistance opportunities for a technologyintegrated One Health approach," Bulletin of the World Health Organization, Vol. 96, pp. 662-664, 2018.

[8] B. Aslam, W. Wang, M. I. Arshad, et al., "Antibiotic resistance: a rundown of a global crisis," Infect Drug Resist., Vol. 11, pp. 16451658, Oct 2018.

[9] F. Prestinaci, P. Pezzotti A. Pantosti, "Antimicrobial resistance: a global multifaceted phenomenon," Pathog Glob Health, Vol.109, pp. 309-318, Sep 2015.

[10] B. Li, and T. J. Webster, "Bacteria antibiotic resistance: New challenges and opportunities for implant-associated orthopedic infections," J Orthop Res., Vol. 36, pp. 22-32, Jan 2018.

[11] S. Thanner, D. Drissner, and F. Walsh, "Antimicrobial Resistance in Agriculture," mBio., Vol. 7, pp. e02227-15, Apr 2016.

[12] V. V. Saharan, P. Verma, A.P. Singh, "Escherichia coli, Salmonella spp., and Staphylococcus aureus susceptibility to antimicrobials of human and veterinary importance in poultry sector of India," J Food Saf, Vol. 40, pp. e12742, Dec 2019.

[13] Q. Chang, W. Wang, G. Regev-Yochay, M. Lipsitch, W. P. Hanage, "Antibiotics in agriculture and the risk to human health: how worried should we be?" Evol Appl., Vol. 8, pp.240-247, Mar 2015.

[14] Y. B. Kim, M. Y. Yoon, J. S. Ha, K. W. Seo, E. B. Noh, et al., "Molecular characterization of avian pathogenic Escherichia coli from broiler chickens with colibacillosis," Poult Sci., Vol. 99, pp. 10881095, Feb 2020.

[15] M. T. Rahman, M. A. Sobur, M. S. Islam, S. Ievy, M. J. Hossain, et al., "Zoonotic Diseases: Etiology, Impact, and Control," Microorganisms, Vol. 8, pp. 1405, Sep 2020.

[16] O. Tenaillon, D. Skurnik, B. Picard, E. Denamur, "The population genetics of commensal Escherichia coli," Nat Rev Microbiol., Vol. 8, pp. 207-217, Mar 2010.

[17] M. Mellata, "Human and Avian Extraintestinal Pathogenic Escherichia coli: Infections, Zoonotic Risks, and
Antibiotic Resistance Trends," Foodborne Pathogens and Disease, Vol.11, pp. 916-932, Oct 2013.

[18] G. Abdukhalilova, L. Kaftyreva, J. A. Wagenaar, B. Tangyarikov, A Bektimirov, I. Akhmedov, et al., "Occurrence and antimicrobial resistance of Salmonella and Campylobacter in humans and broiler chicken in Uzbekistan," Public Health Panorama, Vol. 2, pp. 340-347, 2016.

[19] C. Varga, M.T. Guerin, M .L. Brash, et al., "Antimicrobial resistance in fecal Escherichia coli and Salmonella enterica isolates: a two-year prospective study of small poultry flocks in Ontario, Canada," BMC Vet Res, Vol. 15, pp. 464, Dec. 2019

[20] I. S. Shanta, M. A. Hasnat, N. Zeidner, E. S. Gurley, E. Azziz-Baumgartner, et al., "Raising backyard poultry in rural Bangladesh: financial and nutritional benefits, but persistent risky practices," Transboundary and Emerging Diseases, Vol. 64, pp. 14541464, June 2017

[21] D. V. T. Nair, K. Venkitanarayanan, A. Kollanoor Johny, "AntibioticResistant Salmonella in the Food Supply and the Potential Role of Antibiotic Alternatives for Control," Foods, Vol. 7, pp. 167, June 2018.

[22] H. Al-Talib, H. Hasan, C. Y. Yean, S. M. Al-Ashwal, M. Ravichandran, "Fatal necrotizing pneumonia caused by PantonValentine leukocidin-producing hospital-acquired Staphylococcus aureus: a case report,” Jpn J Infect Dis., Vol, 64, pp. 58-60, 2011.

[23] S. A. Mamza, G. O. Egwu, and G. D. Mshelia, "Beta-lactamase Escherichia coli and Staphylococcus aureus isolated from chickens in Nigeria," Veterinary Italian Journal, Vol. 46, pp. 155-165, 2010.

[24] P. D. Stapleton, and P. W. Taylor, "Methicillin resistance in Staphylococcus aureus," Science Progress, Vol. 85, pp. 57-72, Feb 2002.

[25] M. Cheesbrough, "District Laboratory Practice in Tropical Countries (2nd Edition)," English Language Book Society, London 2006, pp. $100-194$

[26] I. A. Merchant and R. A. Packer, "Veterinary Bacteriology and Virology," 7th edn. TheIowa University Press, Ames, Iowa, USA, 1967. pp. 286-306.

[27] W. Bauer, W. M. M. Kirby, J. Sheris and M. Truck, "Antibiotic susceptibility testing by a standardized single disk method," American J. Clin. Phath., Vol. 145, pp. 225-230, 1966.

[28] E. Pyzik, A. Marek, "Plasmid profile analysis and evaluation of antibiotic susceptibility of Staphylococcus aureus strains isolated from table chicken eggs," Pol J Vet Sci., Vol. 16, pp. 307-312, 2013.

[29] A. Khan, R. Rind, M. Shoaib, A. A. Kamboh, G. A. Mughal, "Isolation, identification and antibiogram of Escherichia coli from table eggs," J. Anim. Health Prod., Vol. 4, pp. 1-5, Dec 2016.

[30] A. Parveen, M. M. Rahman, M. Fakhruzzaman, M. Akter, and M. S. Islam, "Characterization of bacterial pathogens from egg shell, egg yolk, feed and air samples of poultry houses," Asian Journal of Medical and Biological Research, Vol. 3, pp. 168-174, Aug 2017.

[31] S. Chaemsanit, A. Akbar and A. K. Anal, "Isolation of total aerobic and pathogenic bacteria from table eggs and its contents," Food Appl. Biosci. J., Vol. 3, pp. 1-9. April 2015.

[32] M. Salihu, B. Garba and Y. Isah, "Evaluation of microbial contents of table eggs at retail outlets in Sokoto metropolis, Nigeria," Sokoto J. Vet. Sci, Vol. 13, pp. 22-28, 2015.

[33] B. M. Hang'Ombe, R. N. Sharma, L. M. Tuchili and O. Skjerve, "Isolation of bacteria from table eggs in Zambia," Indian J. A. S., Vol. 69 , pp. 445-447, 1999.

[34] USDA (United State Department of Agriculture, Food Safety \& Inspection Services), 2011. Shell eggs from farm to table. www.fsis.usda.gov, retrieved 12-04-2014.

[35] J. Bruce and E. M. Drysdale, Trans-shell transmission, "Microbiology of the avian egg," Chapman and Hall, London. pp. 63-91, 1994.

[36] C. Papadopoulou, D. Dimitriou, S. Levidiotou, H. Gessouli, A. Panagiou, S. Golegou and G. Antoniades, "Bacterial strains isolated from eggs and their resistance to currently used antibiotics: Is there a health hazard for consumers?" Comp. Immunol. Microbiol. Infect. Dis., Vol. 20, pp. 35-40, 1997.

[37] K. R. Jain and R. Yadav, "Study of antibiotic resistance in bacteria isolated from table egg," Int. J. Pharm. Bio. Sci., Vol. 8, pp. 668-674, Jan 2017.

[38] S. Eid, S. A. Nasef and A. M. Erfan, "Multidrug resistant bacterial pathogens in eggs collected from backyard chickens," Assiut Vet. Med. J., Vol. 61, pp. 87-103, Jan 2015.

[39] A. Adesiyun, N. Offiah, N. Seepersadsingh, S. Rodrigo, V. Lashley and L Musai, "Antimicrobial resistance of Salmonella spp. and Escherichia coli isolated from table eggs," Food Cont., Vol. 18, pp. 306-311, 2007. 
[40] A. Kilonzo-Nthenge, S. N. Nahashon, F. Chen and N. Adefope, "Prevalence and antimicrobial resistance of pathogenic bacteria in chicken and guinea fowl," Poult. Sci., Vol. 87, pp. 1841-1848, 2008

[41] I. G. Wilson, "Antimicrobial resistance of salmonella in raw retail chickens imported chicken portions, and human clinical specimens," J. Food Prot., Vol. 67, pp.1220-1225, 2004.

[42] C. M. Schroeder, D. G. White and J. Meng, "Retail meat and poultry as a reservoir of antimicrobial-resistant Escherichia coli," Food Microbiol., Vol. 21, pp. 249-255, 2004.

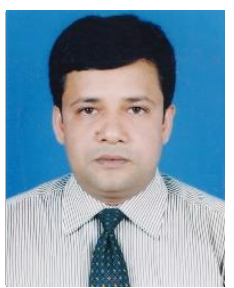

Dr. Md. Hakimul Haque is an Associate Professor in the Department of Veterinary and Animal Sciences, Faculty of Agriculture at the University of Rajshahi, Bangladesh. Dr. Haque completed DVM from Bangladesh Agricultural University (BAU) in 2005. Later he completed a Master of Science (MS) in Microbiology from the BAU in 2007 and received a $\mathrm{PhD}$ from the school of Medicine in collaboration with the School of natural science and Queensland Micro and Nanotechnology Centre, Griffith University in 2017 and a Postdoc from the Griffith University and University of Wollongong, Australia.

Dr. Haque's research has initially focused on bacteria, viruses, fungus, and parasites, to comprehend the impacts of disease damage to agricultural industries. He has worked on epidemiological, serological, and molecular characterization of bacterial, parasitic, and viral pathogens. This work is published in 28 journals at the national and international level. In his $\mathrm{PhD}$ work, he identified several biomarkers and established their relationship for clinical and pathological use in diagnosing oesophageal squamous cell carcinoma. Subsequently, he has developed novel electrochemical and nanotechnology-based diagnostic biosensor platforms using Gold-DNA and Graphene-DNA affinity interactions. This work resulted in several Q1 and Q2 journal publications focused on multidisciplinary research. As a research team leader, Dr. Haque has worked as a supervisor and cosupervisor for $10 \mathrm{MS}$ and $\mathrm{PhD}$ students. 